\title{
Factors Affecting Adoption of a Telemedicine Device by Primary Care Health Workers in the Philippines
}

Portia Grace F. Marcelo, MD, MPH, ${ }^{1,2}$ Kristine Mae M. Magtubo, MD, MPM, ${ }^{2}$ Mark Angelo C. Ang, MD, MoS, ${ }^{4}$ Nathaniel D. Cruz, ${ }^{3}$ Romeo Luis A. Macabasag, MA, ${ }^{2}$ Patrick Joshua C. Pascual, RN, ${ }^{2}$ Geohari L. Hamoy, MD, MPH, ${ }^{2,6}$ Martha Jane Pauline S. Umali, MD, ${ }^{1,2}$ Gene A. Nisperos, MD, ${ }^{1,2}$ Noel R. Juban, MD, MS, ${ }^{7}$ Jonathan G. Fabia, RN, ${ }^{2}$ Abby Dariel F. Santos-Fabia, RN, ${ }^{2}$ Manuel John Paul O. Gaspar, ${ }^{2}$ Luis G. Sison, PhD, ${ }^{3}$ Paul Matthew D. Pasco, MD, MS 1,5

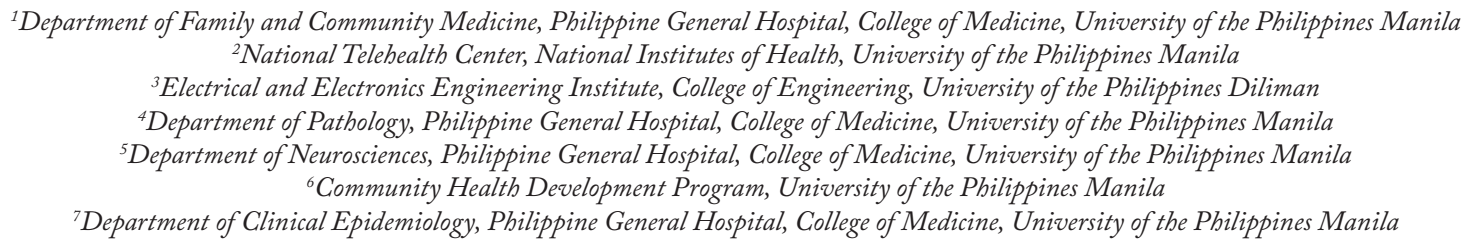

\begin{abstract}
Background and Introduction. The RxBox is a telemedicine device that measures and transmits vital signs to remote experts. It has been deployed to primary care health centers (PCHC) in the Philippines serving disadvantaged populations, to decrease morbidity and mortality due to common diseases and poor access to care. Factors affecting its adoption by healthcare workers is unknown.
\end{abstract}

Materials and Methods. The study determined social and behavioral factors that affect adoption of a telemedicine device into the clinical workflow using the Unified Theory of Acceptance and Use of Technology (UTAUT) framework. This is a mixed methods research using review of records, survey and focused group discussions.

Results and Discussion. RxBox telemedicine devices were installed in 79 primary care health centers (PCHC) and were used a total of 15,705 times within the study period. An ordinary least squares regression analysis using the combined site and individual-level data showed that among the UTAUT parameters, only compatibility, facilitating conditions, and social factors have significant relationships with intent-to-use of the RxBox. The innovation assisted primary care health workers in their clinical responsibilities, improved the stature of their PCHC in the community, and helped in the care for patients. Training and technology support after deployment as well as encouragement by peer and champions (the PCHC physician, local government leaders) reinforced continuous use after training. Users described the experienced improvements in quality of services provided by the PCHC and the consequent benefits to their patients.

Conclusions. These factors should be accounted for in designing strategies to reinforce health workers' attitudes and enhance support towards acceptance and use of novel telemedicine devices into clinical routine in local health centers. Lessons are immediately useful for local leaders in low- and lower middle-income countries that suffer disproportionately from unnecessary maternal deaths and mortality due to non-communicable diseases. This contributes to the body of knowledge and should bolster national-level advocacy to institute an enabling policy on telehealth Information Communication Technology (ICT) and use of Filipino innovations towards health systems strengthening. Results can be used by implementers, evaluators, and regulators of health

Corresponding author: Portia Fernandez-Marcelo, MD, MPH Department of Family and Community Medicine

Philippine General Hospital

College of Medicine

National Telehealth Center

National Institutes of Health

University of the Philippines Manila

547 Pedro Gil Street, Ermita, Manila 1000, Philippines

Email: phfernandezmarcelo@up.edu.ph
ICT, especially in resource-poor settings. Likewise, the study can encourage more research in the field to spur more dynamic local health ICT and biomedical device industries.

Keywords: Telemedicine device, resource-poor and disadvantaged settings, primary Care, UTAUT framework, technology adoption 


\section{INTRODUCTION}

The Philippines continues to experience inequity in access to health services and poor health outcomes among its various population groups. ${ }^{1}$ An archipelagic country in Southeast Asia, the Philippines is beset with a triple disease burden. Non-Communicable Diseases (NCD) cause more than half of all deaths annually; ${ }^{2}$ hypertension and heart diseases are among the leading causes of illnesses each year. ${ }^{3,4}$ Maternal mortality remains high in 2016: 221 Filipino mothers died per 100,000 live births, and a wide range (183 to 260 deaths per 100,000 live births) reflect the inequity across provinces. ${ }^{5}$ The Philippines has Geographically Isolated and socially Disadvantaged Areas (GIDA) with marginalized populations besieged by physical and socioeconomic challenges. ${ }^{6}$

The use of information and communications technology (ICT) have been shown to improve productivity and provide better access to health and education in disadvantaged communities. ${ }^{7,8}$ Telehealth is one such innovation, and is defined as the "delivery of health care services, where patients and providers are separated by distance. It uses ICT for the exchange of information for the diagnosis and treatment of diseases and injuries, research and evaluation, and for the continuing education of health professionals." ${ }^{8}$ (ICT and information technology, or IT, as well as telehealth and telemedicine, are used interchangeably in this article.) Lowand lower middle- income countries have struggled in adopting and thus benefiting from health IT innovations that could help address the greater burden of public health problems. ${ }^{8-10}$

The University of the Philippines Manila (UP) National Telehealth Center (NTHC) pioneered the National Telehealth Service Program (NTSP) to support clinical decisionmaking of over a thousand primary care physicians serving GIDA nationwide. The NTSP research expanded to include the RxBox telemedicine device, capable of measuring physiologic signals: it has a blood pressure monitor, a pulse rate meter and oximeter, an electrocardiogram, a tocometer to measure maternal uterine contraction during labor and a fetal heart monitor. The clinical readings are automatically linked to specific patients' medical information, and stored in the Community Health Information Tracking System (CHITS) electronic medical record (EMR) system. Information is transmitted to medical specialists based in the University hospital from CHITS or directly from the device via telemedicine, using the web-based NTS (National Telehealth Service) application.

Strengthening Maternal and Child Health (MCH) and NCD services in GIDA was the intent of the RxBox telemedicine research: the $\mathrm{RxB}$ ox telemedicine device was designed to incorporate needed sensors for $\mathrm{MCH}$ as well as NCD care. The health IT innovations are equally important as honing relevant and critical competencies in clinical and electronic health information management, embedded in the training and deployment strategies.
Introducing novel technology is often met with problems in its adoption both at the individual ${ }^{11}$ and organizational level. ${ }^{12}$ An innovation is considered successful only if it is absorbed and integrated into the organization, and individuals continue to use it over a period of time. ${ }^{12,13}$ Philippine government investments in telehealth research for GIDA is almost USD 10M across over a dozen years.

Local governments utilize strategies specific to their locale under the devolved set up of health care delivery in Philippines, including testing and pioneering these innovations in health IT. While national health policies strongly influence local health program implementation, national-level policy adoption from this bottom-up process is sluggish.

This study focused on the RxBox device and is intended to gain insight on the use and intent-to-use of this health IT innovation among health professionals serving government primary care health centers (PCHC). The RxBox telemedicine research is pioneering and falls within two national research priorities - health IT and biomedical device development - output of which are envisioned to be enablers of our health system, and of growth of the Filipino health care industry as part of overall socioeconomic development.

This paper aims to provide guidance on how health professionals working in low-resource settings can be best engaged by local, and potentially, national-level leaders, as more health ICT innovations are introduced at the frontlines, and embedded to strengthen health systems.

The Unified Theory of Acceptance and Use of Technology (UTAUT) is applied in this study to explain health worker behavior and health facility use of the RxBox device. ${ }^{11}$ The UTAUT has four main determinants or constructs (Performance expectancy, ${ }^{14-18}$ effort expectancy, ${ }^{14,16,17}$ social influence, ${ }^{15-17}$ facilitating conditions ${ }^{16,19,20}$ ); each is operationalized by sub-constructs. The first three constructs are influenced by four moderators (sex, age, experience, and voluntariness of use), which then affect the intent-to-use and actual use of the RxBox. ${ }^{11,21}$

In addition, the clinical role of the $\mathrm{RxB}$ ox trainee (physician, nurse, midwife, or IT-designate) is hypothesized to be influential in RxBox acceptance and use, as shown by Kijsanayotin, et al., ${ }^{22}$ and Durani, et al. ${ }^{23}$ In government primary care clinics, the physician is typically autonomous and is the health facility leader. Nurses are second in command and designated as the facility health information manager. Midwives are the frontliners in the care of pregnant and parturient mothers. IT-designated officers are the most IT-savvy among health workers in the facility; they are presumed to be the most predisposed to exploring ICT-based innovations in the health center, and would support others in adopting the innovation.

Health facility parameters, including three related to ICT infrastructure found previously to be enabling of innovation adoption were evaluated in the Philippine context: regularity of electricity or power supply, stable 
cellular phone connectivity, and availability of computers in the clinic premises - hypothesized to influence $\mathrm{RxBox}$ use. ${ }^{23-26}$ Relevance and compatibility of the innovations with the organization's mission and processes are valued characteristics; ${ }^{12}$ these were considered as other technologies are integrated in the NTSP. For example, not all PCHC that were recruited had birthing services, but all provide primary ambulatory and emergency care services. Other site characteristics investigated include municipality population and income class, type of GIDA, and date of RxBox training.

The proportion of health workers utilizing computers in the PCHC, and prior exposure of the PCHC to other (NTHC) health IT projects are assessed in their roles in technology adoption. Several previous authors found that IT experience and organizational financial support for IT equipment, are positive factors in innovation adoption..$^{10,11,23,25}$

Timeliness of the receipt of the RxBox after training and its effect on utilization was considered. Due to manufacturing and delivery problems, the majority (71\%) of the recruited health facilities received their RxBox devices three to six months after training.

\section{METHODS}

The protocol for this study was reviewed and approved by the UP-Manila Review Ethics Board.

This descriptive study used mixed research methods - review of records, survey questionnaire, and focused group discussions (FGD). Records reviewed describe the participating health professionals, health facilities and municipalities, RxBox training processes and output, hardware deployment/receipt and utilization, technical issues encountered, and other field observations during the course of project implementation. The survey questionnaire and FGD guide were developed and adapted from previous UTAUT surveys (Table 1); each UTAUT parameter was represented by specific statements. These were pre-tested on health professionals of pioneer RxBox sites. The survey was distributed and collected via email to all 360-health staff trained. A purposive sample of 18 sites that used the RxBox for at least three months were then visited to conduct FGDs and physically administer the survey.

Descriptive statistics of individual and site-level data were summarized using Microsoft Excel 2016. The effects of individual and social factors on health workers (UTAUT constructs, sub-constructs and moderators, and site characteristics) on intent-to-use and actual use were measured using Ordinary Least Squares (OLS) regression models.

Analyses were done on a combination of individual (respondent) and site-level data using the $\mathrm{R}$ statistical software. ${ }^{27}$ Qualitative data was processed using thematic analysis.

Ninety government primary care health centers (PCHC) nationwide were recruited purposively as study sites. Priority was given to poor, rural, and disadvantaged communities, and those whose physicians and local government officials volunteered their communities to participate. Four health workers from each PCHC underwent a four-day training on ethical health information management and ethical use of the RxBox device, CHITS, and telemedicine: the PCHC physician, nurse, midwife, and an IT-designated officer. Cognizant of the devolved set up of health service delivery in the Philippines, researchers directly engaged recruited volunteer sites.

The hardware (device, computer server, and router) were received ready for use immediately after training by 26 PCHC. The majority (64, or $71 \%$, of recruited PCHC), however, received these three to six months after training due to manufacturing and delivery delays.

Utilization of any of the RxBox sensors for at least three months was self-reported by the participating health facility through SMS or emails. Use behavior analysis was done after successful installation; that is, after the trained health staff were able to correctly link the computer with the RxBox device in a local area network, and if available, to the internet.

\section{RESULTS}

The RxBox was deployed to 90 PCHC located in 40 of 81 provinces, in 13 out of 17 regions of the Philippines. Daily minimum wage ranged from 5 to 10 USD in these areas ${ }^{28}$ half of which were the poorest municipalities with annual incomes ranging from less than 300 to 690 USD. Majority of the sites served primarily the rural poor and were island or coastal (54 out of 90 sites, 60\%) while the other 36 sites were landlocked and upland (mountainous) communities. While 86 were rural health units, there were three community emergency hospitals and one city lying-in clinic. Majority of the sites, $64 \%$, serve populations of over 20,000 people, and provide birthing services in addition to maternal and child health $(\mathrm{MCH})$ and general primary care (84\%). Travel time from these facilities to the nearest better equipped referral hospitals ranged from 10 minutes among richer towns, and up to six hours in mountainous areas by land travel. In nine poor island municipalities on the southwest tip of the country, travel was up to 15 hours by boat and cost up to 300 USD, whilst the daily minimum wage in this region was 5 USD. ${ }^{28}$

Regular 24/7 electricity was available in majority (83\%, or 75 out of 90 municipalities). Fifteen towns had irregular and varying qualities of power supply, ranging from six to 18 hours per day delivered by local power suppliers, and mostly available only at night when clinical services were not provided.

While the majority of sites had no available desktop computers or laptops in their health center (53\%), almost all of the participant sites' staff had access to and used a computer (99\%). More than a third (37\%) had been 
Table 1. Definition of the constructs under the Unified Theory on Acceptance and Use of Technology (UTAUT) (Venkatesh, et al., 2003)

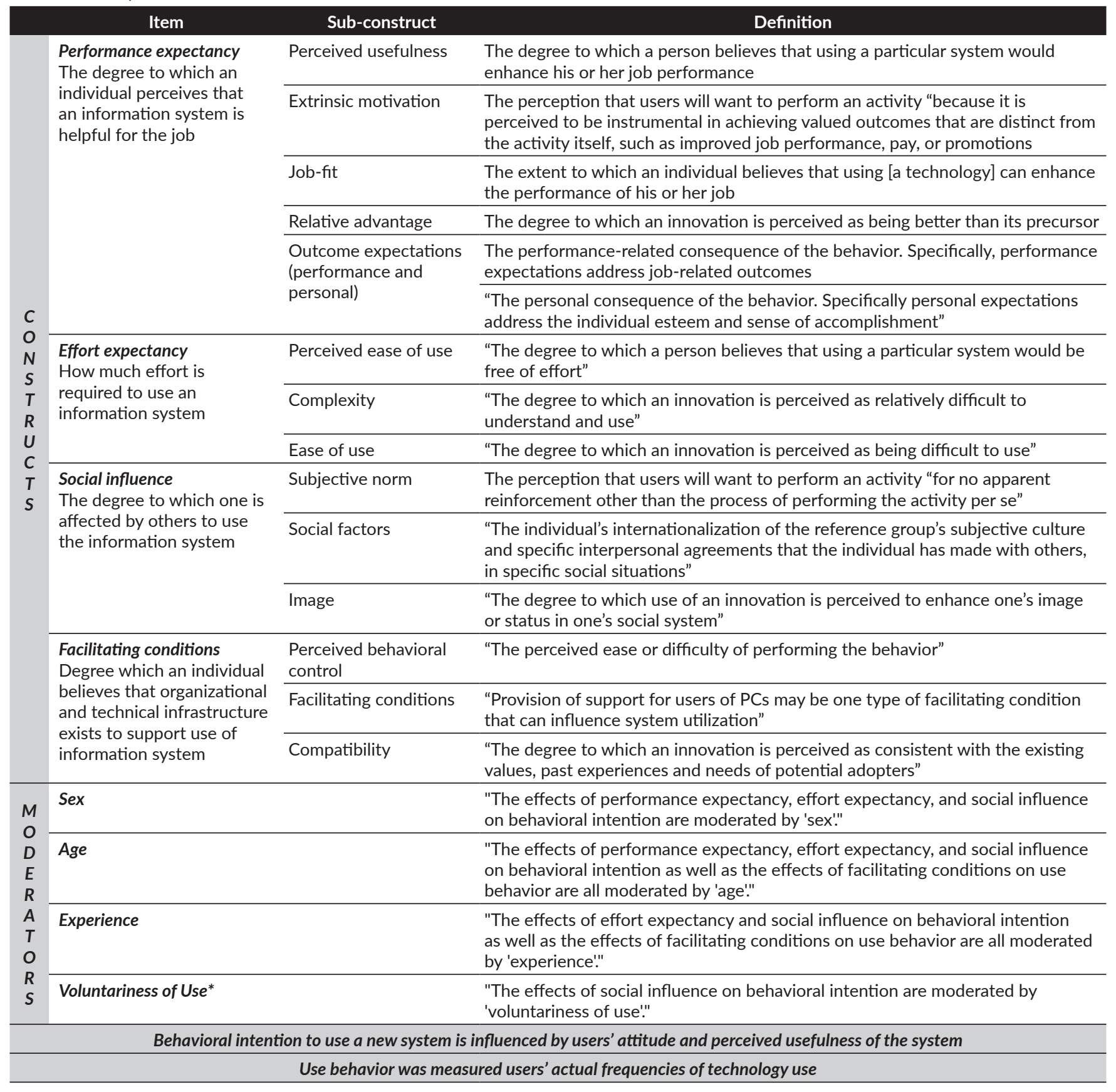

* This moderator was not tested, i.e., participants were recruited from among volunteers to participate in this RxBox study.

partner implementers of previous NTHC health ICT projects (Table 2). $71 \%$ of the sites received the $\mathrm{RxB}$ ox device late; only $29 \%$ received it immediately after training, ready for use.

A total of 99 PCHC staff filled out the survey and were from 32 of the 90 recruited sites. 28 of 32 unique sites were represented by all four health workers who undertook the training, including one site that was unable to install the RxBox within the observation period. Majority of the health worker-survey respondents were females (70\%), physicians and nurses (29\% and 28\% respectively), and considered themselves as having advanced ICT experience (Table 3). Majority were young (39\% fall within the age group of 2030 years old), which meant their clinical practice experience was less than 10 years. These characteristics reflected the general makeup of 360 primary care health workers from the recruited 90 sites. $^{29}$ 
Table 2. Characteristics of Study Sites $(n=90)$

\begin{tabular}{|c|c|c|}
\hline Site characteristics & $\mathbf{n}$ & $\%$ \\
\hline \multicolumn{3}{|l|}{ Population served by the study sites } \\
\hline Less than or equal to 20,000 & 32 & $36 \%$ \\
\hline More than 20,000 & 58 & $64 \%$ \\
\hline \multicolumn{3}{|l|}{ Type of GIDA } \\
\hline Island or Coastal & 54 & $60 \%$ \\
\hline Landlocked or Mountainous & 36 & $40 \%$ \\
\hline \multicolumn{3}{|l|}{ Municipality class* } \\
\hline 1st & 19 & $21 \%$ \\
\hline 2 nd & 11 & $12 \%$ \\
\hline $3 r d$ & 15 & $17 \%$ \\
\hline 4th & 20 & $22 \%$ \\
\hline 5th & 21 & $23 \%$ \\
\hline 6th & 4 & $4 \%$ \\
\hline \multicolumn{3}{|l|}{ Health services } \\
\hline Primary care services & 14 & $16 \%$ \\
\hline Primary care services with a birthing facility & 76 & $84 \%$ \\
\hline \multicolumn{3}{|l|}{ Electricity } \\
\hline Irregular supply & 15 & $17 \%$ \\
\hline Continuous $24 / 7$ supply & 75 & $83 \%$ \\
\hline \multicolumn{3}{|l|}{ Cellular network connectivity } \\
\hline with no network connectivity & 2 & $2 \%$ \\
\hline with 1 or more than 1 network provider & 88 & $97 \%$ \\
\hline \multicolumn{3}{|l|}{ Available PC or laptop/s in the PCHC } \\
\hline No available units & 3 & $3 \%$ \\
\hline with 1 PC or laptop & 12 & $13 \%$ \\
\hline with 2 PCs or laptops & 27 & $30 \%$ \\
\hline with 3 PCs or laptops & 48 & $53 \%$ \\
\hline \multicolumn{3}{|l|}{ Computer use by PCHC staff } \\
\hline No staff uses a computer & 1 & $1 \%$ \\
\hline Less than $30 \%$ of staff use a computer & 42 & $47 \%$ \\
\hline Less than $50 \%$ of staff use a computer & 27 & $30 \%$ \\
\hline Less than $80 \%$ of staff use a computer & 13 & $14 \%$ \\
\hline $100 \%$ staff members use a computer & 7 & $8 \%$ \\
\hline \multicolumn{3}{|l|}{$\begin{array}{l}\text { Prior implementation of an UP National } \\
\text { Telehealth Center project }\end{array}$} \\
\hline None & 57 & $63 \%$ \\
\hline At least one & 33 & $37 \%$ \\
\hline
\end{tabular}

${ }^{*}$ Class is determined through the municipality's annual income in the last four years. The lower the class, the higher income of the municipality.

Majority of PCHC (88\%, or 79 of 90 recruited) installed and reported continuous use of the RxBox. By the end of the study period, 54 PCHC (68.3\% of 79 participating sites) used the device for at least three months, 37 of which (46.8\%) have had at least six months of use. The 79 PCHC reported a combined total of 15,705 instances of device use. Adjusting for the length of time the RxBox was available and usable, each facility used the RxBox device for an average of 14 times weekly.

Using ordinary least squares (OLS) regression analysis, there were no statistically significant associations between the
Table 3. Characteristics of Survey Respondents ( $n=99)$

\begin{tabular}{llrc} 
& \multicolumn{1}{c}{$\begin{array}{c}\text { Survey respondent } \\
\text { characteristics }\end{array}$} & n & $\%$ \\
\hline Sex* & Female & 69 & $70 \%$ \\
& Male & 30 & $30 \%$ \\
\hline Age (yrs.) $^{*}$ & $20-30$ & 39 & $39 \%$ \\
& $31-40$ & 18 & $18 \%$ \\
& $41-50$ & 28 & $28 \%$ \\
& $51-60$ & 14 & $14 \%$ \\
\hline ICT knowledge $_{\text {and experience }}{ }^{* a}$ & Beginner & 1 & $1 \%$ \\
& Intermediate & 11 & $11 \%$ \\
\hline Clinical & Advanced & 85 & $86 \%$ \\
designation & Physician & 29 & $29 \%$ \\
& Nurse & 28 & $28 \%$ \\
& Midwife & 23 & $23 \%$ \\
& IT designated officer & 19 & $19 \%$ \\
\hline
\end{tabular}

* These parameters are identified to be moderators of intent-to-use and use behaviour described by the UTAUT model.

a Basic ICT knowledge is defined as "general knowledge (similar to a college entrant) related to operating a basic personal computer (PC) components and basic functions of PC and the Internet. ${ }^{21}$ ICT knowledge and experience in this study is determined through a self-administered survey that measures user ability to perform computer and internetrelated tasks. From a list of 26 activities, respondents are classified as advanced if they are able to do $\geq 73 \%$ of the tasks; intermediate users are able to do $35 \%$ to $74 \%$; and beginners are able to do $\leq 34 \%$.

UTAUT constructs or moderators with actual utilization, nor between the site characteristics and actual utilization.

When regression of the same set of determinants is done with intent-to-use as the predicted variable, statistically significant positive influences of social factors, facilitating conditions, compatibility, and ICT experience (if beginner) were found (Table 4). The higher the score for social factors, facilitating conditions, compatibility, and lack of ICT experience, the more likely it was that users intended to use the RxBox. The strongest positive correlation was found with lack of ICT experience, though it should be noted that only one respondent was considered lacking in ICT experience (Table 2).

Health professionals from 18 selected municipalities held views on RxBox use that mapped to all constructs and sub-constructs of the UTAUT model (Table 5).

The $\mathrm{RxBox}$ is effective and enabled participants "to accomplish their clinical work" - gathering physiologic measures, monitoring and recording of adult, maternal and fetal health conditions in a manner that is easier, faster, and perceived to be more accurate. It has increased the quality of their work; clinical data made available to them has increased confidence in their own clinical judgment. They reported that they achieved better efficiency, i.e., decreased the time needed for work responsibilities, reduced manpower needed for tasks, allowing them to multi-task.

The innovation increased the integrity of the PCHC by increasing the "confidence of our community members 
Table 4. OLS Regression Analysis of of User and Site Level Parameters (UTAUT Constructs and Moderators) with RxBox Intention to Use

\begin{tabular}{|c|c|c|c|c|c|}
\hline \multicolumn{6}{|l|}{ OLS Linear Regression results } \\
\hline \multicolumn{6}{|c|}{ Dependent variable: RxBox Intention-to-use } \\
\hline & & Coeff. & Std. Error & $\mathrm{t}$-value & $p$ value \\
\hline Intercept term for the model & & 0.950 & 0.514 & 1.849 & 0.069 \\
\hline \multirow[t]{5}{*}{ Performance Expectancy } & Perceived usefulness & -0.149 & 0.124 & -1.201 & 0.234 \\
\hline & Extrinsic motivation & 0.141 & 0.126 & 1.114 & 0.27 \\
\hline & Job fit & -0.011 & 0.131 & -0.086 & 0.932 \\
\hline & Relative advantage & -0.158 & 0.180 & -0.875 & 0.385 \\
\hline & Outcome expectations & -0.106 & 0.119 & -0.897 & 0.373 \\
\hline \multirow[t]{3}{*}{ Effort Expectancy } & Perceived ease of use & -0.091 & 0.167 & -0.545 & 0.588 \\
\hline & Complexity & -0.105 & 0.063 & -1.661 & 0.101 \\
\hline & Ease of use & 0.273 & 0.154 & 1.766 & 0.082 \\
\hline \multirow[t]{3}{*}{ Social Influences } & Subjective norm & -0.074 & 0.086 & -0.856 & 0.395 \\
\hline & Social Factors & 0.213 & 0.098 & 2.185 & $0.032 *$ \\
\hline & Image & -0.002 & 0.126 & -0.017 & 0.987 \\
\hline \multirow[t]{3}{*}{ Facilitating Conditions } & Perceived behavioral control & -0.175 & 0.115 & -1.525 & 0.132 \\
\hline & Facilitating conditions & 0.321 & 0.085 & 3.767 & $0.000 \neq$ \\
\hline & Compatibility & 0.763 & 0.108 & 7.038 & $0.000 \neq$ \\
\hline \multirow[t]{4}{*}{ UTAUT moderators } & Age & -0.007 & 0.005 & -1.479 & 0.144 \\
\hline & Sex (if Male) & -0.028 & 0.113 & -0.251 & 0.802 \\
\hline & ICT knowledge and experience (if Beginner) & 0.996 & 0.453 & 2.198 & $0.031 *$ \\
\hline & ICT knowledge and experience (if Intermediate) & -0.022 & 0.157 & -0.137 & 0.891 \\
\hline \multirow{3}{*}{$\begin{array}{l}\text { Clinical } \\
\text { Designation }\end{array}$} & Physician & 0.018 & 0.144 & 0.127 & 0.900 \\
\hline & Nurse & -0.046 & 0.138 & -0.33 & 0.742 \\
\hline & Midwife & 0.068 & 0.154 & 0.445 & 0.658 \\
\hline Weeks the device was on site & & -0.003 & 0.003 & -0.796 & 0.429 \\
\hline \multirow[t]{4}{*}{ Model statistics: } & \\
\hline & \multicolumn{5}{|c|}{ (63 observations deleted due to missingness) } \\
\hline & \multicolumn{5}{|c|}{ Multiple R-squared: 0.8043, Adjusted R-squared: 0.7437} \\
\hline & \multicolumn{5}{|l|}{ F-statistic: 13.27 on 22 and 71 DF, p-value: $<2.2 \mathrm{e}-16$} \\
\hline
\end{tabular}

Signif. codes: ${ }^{*} p$ value $<0.05 ;{ }^{\dagger} p$ value $<0.01 ;{ }^{\ddagger} p$ value $<0.001$

to consult in our center." By expanding the diagnostic capability of the PCHC, needed diagnostic services are now available and accessible to the community, allowing more immediate care.

Criticisms of the innovation were in three areas. The first reflected inertia or resistance to change: "Rather than getting used to the manual encoding, there is additional work for us [by having to learn and use the RxBox]." Some found the device complex to use, and attributed this to their more advanced age and consequent lack of background on ICT. The second was on device technology issues: some reported the RxBox to become unresponsive and the screen becomes hypersensitive, thus the images become blurred. The third was on the poor infrastructure in the poor rural communities targeted in this study: as an electronic device, continuous use was affected by lack of regular power supply in the research sites.

\section{DISCUSSION}

This study found that none of the constructs or moderators described by the UTAUT model affected actual use of the RxBox. Whilst used thousands of times within the study period, the pattern of RxBox use by the study participants cannot be explicitly explained by the UTAUT parameters, community and demographic profiles of study participants. The PCHC in the study, despite their geographic spread across the Philippines, do not possess sufficient variability to produce statistically significant predictors of continuous RxBox use.

However, intent-to-use the $\mathrm{RxBox}$ is positively influenced by the constructs facilitating conditions (subconstructs compatibility and facilitating conditions) and social influence (sub-construct social factors). 
Table 5. Use of the RxBox: Thematic Analysis of Focused Group Discussions with Primary Care Health Workers ( $\mathrm{n}=18 \mathrm{PCHC}$ )

\begin{tabular}{|c|c|c|}
\hline $\begin{array}{l}\text { UTAUT } \\
\text { Construct }\end{array}$ & $\begin{array}{c}\text { UTAUT } \\
\text { Sub-construct }\end{array}$ & $\begin{array}{l}\text { Common Themes } \\
\text { (Use and intent-to-use the RxBox was influenced by..) }\end{array}$ \\
\hline $\begin{array}{l}\text { Performance } \\
\text { expectancy }\end{array}$ & $\begin{array}{l}\text { Perceived } \\
\text { usefulness } \\
\text { and job fit }\end{array}$ & $\begin{array}{l}\text { 1. Better quality data emanating from the RxBox } \\
\text { a. More accurate than manually collected data (ex. fetal heart tones more audible, ECG tracing available } \\
\text { vs. clinical history and physical findings alone) } \\
\text { b. Provides evidence, more objective basis for diagnosis } \\
\text { c. Results becomes basis for referral for more complex care } \\
\text { 2. Support is provided to health professionals } \\
\text { a. Increased confidence when provided with sound/objective basis of clinical judgement } \\
\text { b. Ease in performance of duty (i.e., monitoring and gathering of patient physiologic data) } \\
\text { c. Better efficiency: reduced time to accomplish work } \\
\text { d. Perceived safer patient care }\end{array}$ \\
\hline
\end{tabular}

Criticisms:

1. Inconvenience of having to learn to use new devices

2. Device issues: sensitive screen, "hangs", higher blood pressure reading

Extrinsic 1. Cases are resolved in the PCHC without needing to refer patients outside of the municipality -

motivation 2. Patients benefits: convenience, care services became, available, accessible and affordable

3. Patients positively perceptions of the PCHC

a. Perceive "High tech" services are now available

b. Increased trust in quality care provision by $\mathrm{PCHC}$

c. Increased number of consults in the PCHC

Relative 1. Services in are now available and accessible to the community

advantage a. RxBox has expanded the diagnostic capability of the PCHC

2. Patient safety: More accurate, less errors

3. Good for patients: Allow early diagnosis

4. Assist health workforce

a. Reduced manpower needed for tasks

b. Health staff can multi task

c. Automated: Reduced time for tasks

d. Ease of work due to the "all-in-one" compact device

e. Device portability

Outcome 1. Enhanced personal professional knowledge in the use of technology

expectations 2. Improved morale of health workers and trust in the PCHC

3. Increased self-esteem from patient trust

4. Increased comfort and convenience for the patients a. RxBox has made healthcare affordable.

\begin{tabular}{|c|c|c|}
\hline \multirow[t]{3}{*}{$\begin{array}{l}\text { Effort } \\
\text { expectancy }\end{array}$} & $\begin{array}{l}\text { Perceived } \\
\text { ease of use }\end{array}$ & $\begin{array}{l}\text { 1. Easy to use } \\
\text { 2. Difficult at first but eventually becomes easier to use. Constant use is helpful. }\end{array}$ \\
\hline & \multirow[t]{2}{*}{ Complexity } & 1. Constant use increases confidence in its use \\
\hline & & $\begin{array}{l}\text { Criticisms: } \\
\text { 1. Lack background in using ICT, more senior/older health worker with no experience nor training on ICT use } \\
\text { 2. Device is dependent on electricity, when the municipality has lack of regular power supply }\end{array}$ \\
\hline \multirow[t]{2}{*}{$\begin{array}{l}\text { Social } \\
\text { influence }\end{array}$} & Social factors* & $\begin{array}{l}\text { 1. Use was influenced by the doctor } \\
\text { 2. Local government unit (LGU) support } \\
\text { 3. Local government staff now use PCHC services } \\
\text { 4. Engaged and supported to use the device by peers who are early adopters }\end{array}$ \\
\hline & Image & $\begin{array}{l}\text { 1. Increased trust and confidence of patients in the services of the PCHC } \\
\text { 2. Increased consults at the PCHC } \\
\text { 3. Pride in being a better equipped PCHC } \\
\text { 4. Increased patient satisfaction, increased patient pride and morale } \\
\text { 5. Patients were more disciplined, followed up more regularly }\end{array}$ \\
\hline \multirow[t]{4}{*}{$\begin{array}{l}\text { Facilitating } \\
\text { conditions }\end{array}$} & \multirow{2}{*}{$\begin{array}{l}\text { Perceived } \\
\text { behavioral } \\
\text { control }\end{array}$} & $\begin{array}{l}\text { 1. Health staff have background in using technology } \\
\text { 2. Constant use increased confidence }\end{array}$ \\
\hline & & $\begin{array}{l}\text { Criticisms: } \\
\text { 1. Personal limitation (being old, with poor vision) } \\
\text { 2. Lack of knowledge background on ICT use }\end{array}$ \\
\hline & $\begin{array}{l}\text { Facilitating } \\
\text { conditions* }\end{array}$ & $\begin{array}{l}\text { 1. Training was sufficient } \\
\text { 2. User Manuals were available as reference } \\
\text { 3. Influenced by the RxBox team follow-up } \\
\text { 4. Supervision, peer support and external help desk }\end{array}$ \\
\hline & Compatibility* & $\begin{array}{l}\text { 1. Needed physiologic information for care was immediately made available } \\
\text { 2. Device was meant and designed for the PCHC health worker }\end{array}$ \\
\hline
\end{tabular}

\footnotetext{
${ }^{*}$ Factors or sub-constructs found to be statistically significant to affect reported intent-to-use by primary care health workers through OLS regression analysis.
} 
These are starting points for local and even national level leaders to foster use of emerging telehealth technologies towards health systems strengthening. As more is invested in these three sub-constructs, the stronger will be their influence in motivating potential technology adopters.

Policy, organizational and technical support to predispose, enable and reinforce health worker use of innovations as they render clinical care must be in place. With high maternal deaths, $\mathrm{PCHC}$ nationwide have been the focus of national and international support to be equipped with basic emergency obstetric and neonatal care capacities. Likewise, the Philippine Package of Essential NCD Interventions and its incorporation in the country's national insurance program are country investments in curbing NCD morbidity and mortality. Whilst these are national-level policies, local government health offices are expected to implement these in their locale. The National Telehealth Service Program, which incorporated and seamlessly linked the RxBox and CHITS technologies, designed the training-deployment strategy, premised to support these Philippine health priorities.

Common themes raised during the FGD with the health staff relate to the experienced improved quality of services provided the PCHC and the consequent benefits to their patients. Compatibility was validated in this study to be a significant factor in behavioral intention to adopt the $\mathrm{RxBox}$ by the targeted health personnel. PCHC staff reported that use of the device is consistent with their workflow: "as a midwife, I appreciate the tocometer, fetal heart monitor and partograph of the RxBox. It has made my work easier especially during birthing processes." They have "better diagnostic capacities," improving efficiency, than merely relying on their clinical acumen. Statements expressed by PCHC workers similarly echo statements categorized under UTAUT subconstructs of perceived usefulness/job fit and as well as relative advantage: the RxBox was viewed to be beneficial and aids in patient care.

Users reported appreciation for the new equipment introduced to their PCHC; greater confidence in their clinical capacities was fostered. Objective physiologic data captured by the RxBox biomedical device confirms what primary care physicians have already clinically deduced and arms them with better evidence to confidently refer critical patients to the hospitals. Physician-respondents in the study cite previous experiences where hospital-based clinicians scoff at the PCHC for referring patients late in the course of the disease - a lament reflecting the mistrust and lack of a sense of connectedness in the local referral system.

With the introduction of the device, needed diagnostic services, $\mathrm{RxB}$ ox $\mathrm{MCH}$ sensor suite and ECG for NCD care were now available, accessible and thus more affordable to the community ("they need not travel to the provincial capital, we now have the ECG here"). Health workers cited increased patient satisfaction especially now that clinical information about their health status was made instantly available. For example, respondents said that "the mothers are happy, when they hear their baby's heartbeat," which was a shared positive experience reported among many of the RxBox sites. It has contributed to improving the dignity of patients ("that even if they are 'just' rural folk, they (are worthy to) have high tech services" available for their care). It has increased community trust in their PCHC. For the users, innovations "created a good impression (about the PCHC) on the community." It encouraged good healthseeking behavior from the community: "Mothers seek care more regularly; the number of patients has increased." "Even the local government personnel now consult at the Center;" the observation reflects the PCHC staff's pride in that even the middle class, not just the poor, now consult in their clinic when they started using the health IT innovations. These contributed to improved self-esteem and morale of health workers; that they have done their job in improving PCHC systems, affirming their duty-bearer roles.

Regardless of clinical roles, age, sex and IT experience, respondents put a high degree of importance to the compatibility construct: the device should be consistent with their existing contexts. The process of adoption is multistaged: pre-adoption, adoption-decision and post-adoption (implementation stage where the innovation is acquired). ${ }^{12}$ Design of the product, the support systems as well as messages around the innovation should be clear: the new technology should be supportive of the intended-users' work, should fit well with the way they "like to work," and should fit into user's work style.

While Kijsayanotin et al. found that facilitating conditions construct positively influence actual use and not intention-to-use, ${ }^{22}$ this study shows otherwise: facilitating conditions positively influence intention-to-use, but not actual use. Several other studies also bear this association. ${ }^{30-33}$ Ajzen found that facilitating conditions are significant when performance expectancy and effort expectancy are absent. ${ }^{19}$ When organizational efforts are put in place to help and support behavior change, impediments to sustained use are supposedly removed. ${ }^{11,19}$ The sub-construct facilitating conditions that predispose and reinforce behavioral intention to use the innovation is attributed to the training and deployment activities of the RxBox, CHITS EMR and NTS telehealth platform. The four-day seminar workshop was process-oriented, role-based, and directed towards mastery building. Health workers were provided user manuals. Further, a post-deployment service where users were given support for technology issues they encounter. The virtual presence and constant contact through technical support service were cited by the health center staff to promote continuous use. ${ }^{34}$

Social influence is found to be a significant factor in several other studies among health professionals. ${ }^{22,35-39}$ This study underscores the positive influence of UTAUT sub-construct social factors. PCHC professionals tend to use the device "because my co-workers use it," and when colleagues endorse it, "we are influenced when nurses from 
other municipalities would tell us about their experience with the RxBox." Users reported that health workers tend to support each other in learning new innovations to facilitate PCHC tasks.

This study affirms that health care in the Philippines to be heavily influenced by leaders within the social circle of the health workers: they are authoritative even in the use of new technology ("If the doctor will advise us to use the device, we would comply and use it. We also ask for permission if he would allow us to use the device"). Conversely, health workers cited that the loss of the physician as a reason for the irregular and eventual discontinued use of the device. Half of the study sites were served by new medical school graduates salaried by the national government to serve isolated communities for two years. When their contracts expired, the community likewise lose the innovation champions. New technologies introduced to $\mathrm{PCHC}$ warrant more focus on enabling doctors to perform this role of health IT advocate.

Social influence is significant only when ICT use is mandated; when it is voluntary, social influence is insignificant. $11,15,17$ While the health professionals were recruited voluntarily, perceptions of their leaders on new technology is shown to positively shape user perceptions. During FGDs, health workers valued the guidance, encouragement and support they get from the local government chief executives. This support was seen in at least five ways: ${ }^{29}$ funding for travel to attend the training, prompt procurement of needed auxiliary equipment, enactment of local ordinances to sustain new technologies, designation of municipal IT personnel to support the PCHC, and encouraging younger health professionals assigned to use the innovation. Health workers were especially encouraged when the local chief executives' avail of services at the health center: "the municipal officials are swayed to have their clinical check-up in the center, unlike before where they choose to seek care elsewhere." Thus, courting local government support should be a mainstay in introducing health IT innovations.

Despite over a dozen years of telehealth research of the UP, even if these have informed telehealth bills filed in the Congress and draft executive policy instruments for national implementation, telehealth remains in the realm of smallscale, project-based endeavors without an enabling policy. Adoption at the national-level remains an uphill battle.

Findings from this study should thus bolster argument for the enabling role of telehealth in the country, especially for GIDA. This study contributes to the sparse literature on health IT from low- and lower middle-income countries which disproportionately suffer from maternal and NCD deaths, where the country's level of expertise, access, and availability of life-saving medical technologies are lacking.

Following Venkatesh and others, sex and age of the user are expected to moderate social influence. ${ }^{14}$ In this study, neither was seen to be correlated with the construct. Interestingly, intention-to-use is negatively influenced by the moderator ICT experience, i.e., the less experienced the targeted user is, the more predisposed one is to use the RxBox. This is contrary to views of users during the FGD: discussants reported that they find the device easier to use especially when they have previously used computers or tablets. However, it should be mentioned that only one respondent was considered as lacking ICT experience. This should be examined further, or the questionnaire can be administered to more respondents with limited ICT experience, to determine why this single respondent was able to produce such a significant association.

None of the health facility parameters affected actual use of the RxBox in the targeted PCHC. GIDA characteristics (geographic area type and degree of poverty) likewise did not affect intent-to-use of the RxBox. Infrastructure in these communities are typically problematic, and are thought to add another layer of complexity to technology adoption. Yet this study did not find regularity of electricity or power supply, stable cellular phone connectivity, and availability of computers in the clinic premises to affect innovation adoption.

Previous experience with health IT is found to be enabling ${ }^{11}$ but this was not supported by this study. The proportion of health workers utilizing computers in the $\mathrm{PCHC}$, and prior exposure of the PCHC to other NTHC health IT projects also did not affect technology adoption. In addition, having a busy clientele in the PCHC (wherein the RxBox might be used more often) and even delayed receipt and use of the RxBox devices did not affect intent-touse nor use of the innovation.

These findings are likely explained by the relative homogeneity of characteristics of the few volunteer sites. Whereas previous studies have identified enablers and deterrents akin to the parameters evaluated in this study, a larger implementation project would perhaps demonstrate the expected associations of innovation adoption. Only 360 users were recruited in the project, a characteristic categorized only as a pilot implementation by the World Health Organization (WHO).

Criticisms by the primary care health workers include device technology issues: such as the RxBox becoming unresponsive and the screen becoming blurred. Whilst these are rooted in both human and technology factors, these do not belie that the deployed device is still a prototype in a research and development process. Nevertheless, technology failure can discourage use and intent-to-use. Researchers have to manage better user expectations and obviate potential reputational loss during these early stages of technology and manufacturing readiness.

There are several limitations in this study. First, combining individual-level data with the organizational level data can lead to aggregation bias where there could be an over- or underestimation of the predictive power of individual-level data. ${ }^{12,40,41}$ Second, a factor approach to understanding innovation acceptance can be incomplete 
and should be cognizant of the dynamic processes within the organization into which the health IT is introduced and the larger context of this organization (ICT infrastructure, policy and resources, as well as the actions of the innovation champions). The UTAUT Model explains individual technology adoption behavior, albeit influenced by the environment the health worker is in. Hameed and others, ${ }^{12}$ Khoja, Durani, and $\mathrm{Scott},{ }^{42}$ and the $\mathrm{WHO}^{43}$ posit a model for health IT adoption as a sequence of stages, and an interactive process between the user and the context one is in.

Research results should be regarded in the light that while health service delivery is devolved to over 1700 local government units (municipalities, cities, provinces), they are expected to follow centrally-developed health policies. While local governments have been eager partners in testing and pioneering telehealth innovations, national-level policy adoption has plodded through a myriad of challenges, including varied priorities, the lack of evidence and/or perhaps a weak advocacy strategy among researchers.

Third, the pattern of RxBox use by the study participants, albeit spread throughout the Philippine archipelago, cannot be entirely accounted for by the UTAUT parameters, community and demographic profiles of study participants. A larger sample size than 79 PCHC that implemented the $\mathrm{RxB}$ ox is recommended.

Excluded from analysis were 11 sites which encountered device issues upon receipt. This includes four nonimplementing facilities which appear to have not installed nor tried using the RxBox system at all despite repeated attempts to contact these by research staff throughout the observation period. While reasons for potential non-use can be instructive, these were not collected from these sites due to resource limitations of this research.

The study was limited to health facilities that could afford to volunteer and install the $\mathrm{RxBox}$ system. This required a local counterpart in terms of travel expenses of the four health professionals per PCHC for the training, allowing health services to be reduced due to the absence of these health staff, and additional computer equipment for their health center to install and implement the innovation.

Finally, while some research had a minimum of six months study period, the project duration limited the observation period to three months upon installation for some that received devices that were manufactured and delivered late to the PCHC.

\section{CONCLUSIONS}

This study examined and explained factors for adoption of the RxBox telemedicine device in health centers across the Philippines. Facilitating conditions (the training and training manuals, and continuous technical support after the training), compatibility with clinical workflow and job demands, and social factors were the most important factors related to intent-to-use of the RxBox.
The examination of behavioral intention is only the first step to evaluate the effectiveness of this telemedicine device. A study is recommended to evaluate health outcomes of introduction of this innovation, to establish that current empirical evidence on the benefits of telemedicine and allied devices has solid basis.

The research contributes to defining policy, operational and social considerations as input for other health IT and biomedical device innovations intended for GIDA. Results of this study are expected to guide the large-scale implementation of the RxBox device with the CHITS integrated in the National Telehealth Service Program. Results can be used in devising strategies to reinforce positive attitudes of health workers towards accepting and advocating for innovation, and other measures to integrate telemedicine and use of medical devices into daily work routine of frontline health facilities.

The study results can contribute to the body of knowledge in instituting policy about telehealth ICT and use of Filipino innovations towards health systems strengthening. They can be useful for implementers, evaluators, and regulators of digital health, especially in resource-poor settings. These are steps to expand the pool of researchers in related fields and to stimulate the growth of local health IT and biomedical device industries.

\section{Acknowledgments}

The authors are thankful to the contributions of all primary care health workers in PCHC and leaders of 169 local governments (municipalities, cities, provinces and congressional districts), provincial health officers, Western Visayas State University, Bataan State Peninsula University, UP Visayas, the Department of Health and the Department of Science and Technology (national and regional offices), the UP Manila NTHC (Telehealth, RxBox, CHITS) research assistants, project consultants, UP medical specialists and faculty, and the UP Manila and UP Diliman administration for contributions to the implementation, and definition of clinical, technology, operations and policy issues and lessons related to the integration of medical devices in the National Telehealth Service Program.

\section{Statement of Authorship}

All authors participated in the conceptualization, data collection, data analysis, and approved the final version submitted.

\section{Author Disclosure}

All authors declared no conflicts of interest.

\section{Funding Source}

This paper is an output of a project funded by Philippine Council for Health Research and Development of the Department of Science and Technology from 2012-2017. 


\section{REFERENCES}

1. Romualdez AG Jr, dela Rosa JF, Flavier JD, Quimbo SL, HartiganGo KY, Lagrada LP, et al. The Philippines Health System Review [Internet]. Health Systems in Transition. Manila: World Health Organization Regional Office for the Western Pacific; 2011 [cited 2017 Jul 17]. Available from: https://apps.who.int/ iris/bitstream/handle/10665/207506/9789290615583_eng. pdf? sequence $=1$ \&isAllowed $=$

2. Department of Health. The 2013 Philippine Health Statistics [Internet]. Manila: Department of Health; 2013 [cited 2017 Jul 17]. Available from: http://www.doh.gov.ph/sites/default/files/ publications/2013PHScompressed_0.pdf

3. World Health Organization. WHO Country Cooperation Strategy: Philippines [Internet]. Manila: World Health Organization Regional Office for the Western Pacific; 2015. [cited 2017 Jul 17]. Available from: http://apps.who.int/iris/bitstream/10665/136828/1/ccsbrief_ phl_en.pdf.

4. Department of Health. Field Health Service Information System Annual Report 2015 [Internet]. Manila: Department of Health; 2013 [cited 2017 Jul 17]. Available from: Manila: Department of Health; 2015. http://www.doh.gov.ph/sites/default/files/publications/2015_ FHSIS_0.pdf.

5. National Economic and Development Authority; United Nations Development Programme. The Philippines: Fifth Progress Report - Millennium Development Goals [Internet]. Manila: National Economic and Development Authority; 2014 [cited 2017 Jul 18]. Available from: http://www.neda.gov.ph/wp-content/uploads/2014/ 08/PH-5TH-MDG-PROGRESS-REPORT_Nov-4-ver.pdf.

6. Department of Health Administrative Order 185: Establishing of the Geographically Isolated and Disadvantaged Areas (GIDA) in Support to Local Health Systems Development; Manila: Department of Health; 2004.

7. Kvedar J, Coye MJ, Everett W. Connected health: A review of technologies and strategies to improve patient care with telemedicine and telehealth. Health Aff. 2014; 33(2):194-99. doi:10.1377/ hlthaff.2013.0992.

8. World Health Organization. Global Health Observatory (GHO) data [Internet]. Analysis of third global survey on eHealth based on the reported data by countries; 2016 [cited 2020 Jul 16] Available from: https://www.who.int/gho/goe/telehealth/en

9. Macabasag RL, Magtubo KM, Fernandez-Marcelo PG. Implementation of Telemedicine Services in Lower-Middle Income Countries: Lessons for the Philippines. J Int Soc Telemed eHealth. 2016; 4:e24-1.

10. Oluoch T, de Keizer NF. Evaluation of health IT in low-income countries. In: Ammenwerth E, Rigby M, editors. Evidence-Based Health Informatics. Amsterdam: IOS Press Book Series in Studies in Health Informatics; 2016. p. 324-35.

11. Venkatesh V, Morris MG, Davis GB, Davis FD. User acceptance of information technology: Toward a unified view. MIS Quarterly. 2003; 27(3):425-78.

12. Hameed MA, Counsell S, Swift S. A conceptual model for the process of IT innovation adoption in organizations. J Eng Tech Manage. 2012/7; 29(3):358-90. doi:10.1016/j.jengtecman.2012.03.007

13. Gopalakrishnan S, Damanpour F. A review of innovation research in economics, sociology and technology management. Omega. 1997; 25(1):15-28. doi:10.1016/S0305-0483(96)00043-6.

14. Venkatesh V, Davis FD. A theoretical extension of the technology acceptance model: Four longitudinal field studies. Manage Sci. 2000; 46(2):186-204. doi:10.1287/mnsc.46.2.186.11926.

15. Davis FD, Bagozzi RP, Warshaw PR. Extrinsic and intrinsic motivation to use computers in the workplace. J Appl Soc Psychol. 1992; 22(14):1111-32. doi:10.1111/j.1559-1816.1992.tb00945.x.

16. Thompson RL, Higgins CA, Howell JM. Personal computing: Toward a conceptual model of utilization. MIS Q. 1991; 15(1):125-43. doi:10.2307/249443
17. Moore GC, Benbasat I. Development of an instrument to measure the perceptions of adopting an information technology innovation. Information Systems Research. 1991; 2(3):192-222. doi:10.1287/ isre.2.3.192.

18. Compeau DR, Higgins CA. Computer self-efficacy: Development of a measure and initial test. MIS Q. 1995; 19(2):189-211. doi:10.2307/249688.

19. Ajzen I. From intentions to actions: A theory of planned behavior. In: Kuhl PD, Beckmann J, editors. Action Control: Berlin: SSSP Springer Series in Social Psychology; 1985. p. 11-39.

20. Rogers EM. Diffusion of Innovations. 4th ed. New York: The Free Press; 2010.

21. Venkatesh V, Morris MG. Why don't men ever stop to ask for directions? Sex, social influence, and their role in technology acceptance and usage behavior. MIS Q.2000; 24(1):115-39. doi:10.2307/3250981.

22. Kijsanayotin B, Pannarunothai S, Speedie SM. Factors influencing health information technology adoption in Thailand's community health centers: Applying the UTAUT model. Int J Med Inform. 2009; 78(6):404-16. doi:10.1016/j.jmedinf.2008.12.005.

23. Durrani H, Khoja S. A systematic review of the use of telehealth in Asian countries. J Telemed Telecare. 2009; 15(4):175-81. doi: 10.1258/ jtt.2009.080605.

24. Jennett PA, Gagnon MP, Brandstadt HK. Preparing for success: readiness models for rural telehealth. J Postgrad Med. 2005; 51(4):27985. https://www.ncbi.nlm.nih.gov/pubmed/16388170.

25. Li J, Land LPW, Ray P, Chattopadhyaya S. E-Health readiness framework from Electronic Health Records perspective. International Journal of Internet and Enterprise Management. 2010; 6(4):326-48. doi:10.1504/IJIEM.2010.035626.

26. Halamka J, Aranow M, Ascenzo C, et al. E-Prescribing collaboration in Massachusetts: Early experiences from regional prescribing projects. J Am Med Inform Assoc. 2006; 13(3):239-44. doi:10.1197/jamia. M2028.

27. R Core Team. R: A language and environment for statistical computing. R Foundation for Statistical Computing, Vienna; 2013 [cited 2017 Jul 18]. Available from: https://www.r-project.org/

28. National Wages and Productivity Commission. 2015 Annual Report. Manila, the Philippines: Manila: Department of Labor and Employment; 2015 [cited 2017 Jul 18]. Available from: http://nwpc. dole.gov.ph/pages/download/2015\%20Annual\%20Report\%20Final. pdf.

29. Fernandez-Marcelo P. RxBox2: Field Deployment of Telemedicine Devices. Manila: University of the Philippines Manila National Telehealth Center; 2016

30. Cimperman M, Brenčič MM, Trkman P. Analyzing older users' home telehealth services acceptance behavior-applying an Extended UTAUT model. Int J Med Inform. 2016; 90:22-31. doi: 10.1016/ j.ijmedinf.2016.03.002

31. Maillet É, Mathieu L, Sicotte C. Modeling factors explaining the acceptance, actual use and satisfaction of nurses using an Electronic Patient Record in acute care settings: An extension of the UTAUT. Int J Med Inform. 2015; 84(1):36-47. doi:10.1016/j.ijmedinf.2014.09.004.

32. Vanneste D, Vermeulen B, Declercq A. Healthcare professionals' acceptance of BelRAI, a web-based system enabling person-centered recording and data sharing across care settings with interRAI instruments: A UTAUT analysis. BMC Med Inform Decis Mak. 2013; 13:129. doi:10.1186/1472-6947-13-129.

33. van der Vaart R, Atema V, Evers AWM. Guided online selfmanagement interventions in primary care: A survey on use, facilitators, and barriers. BMC Fam Pract. 2016; 17:27. doi:10.1186/s12875-0160424-0.

34. Macabasag RL, Dino MJ. Understanding the essence of caring from the lived experiences of Filipino informatics nurses. Nur Sci Q. 2018; 31(2):166-74. doi:10.1177/0894318418755732

35. Ongkeko AM Jr., Fernandez RG, Sylim PG, Amoranto AJ, RonquilloSy MI, Santos AD, et al. Community Health Information and Tracking System (CHITS): Lessons from eight years implementation of a pioneer electronic medical record system in the Philippines. Acta Med Philipp. 2016; 50(4):264-79. 
36. Fernandez-Marcelo P, editor. Partnership Matters: Lessons from a Decade of Community-University Collaboration in Community and Local Health Systems Development. Manila: University of the Philippines Manila College of Medicine; 2010.

37. Premji S, Scott RE, Currie G. The Development of a Framework to Evaluate the Organisational and Policy Impacts of the Community Health Information Tracking System (CHITS) in the Philippines: Final Report [Internet]. Alberta, Canada: University of Calgary; 2010. [cited 2017 Jul 17]. https://www.academia.edu/36582560/The Development_of_a_Framework_to_Evaluate_the_Organizational_ and_Policy_Impacts_of_CHITS_in_the_Philippine

38. Germonpré S, Gemmel P, Beeckman D. Determinants of using (non-) fluoroscopy-guided positioning for radiographs: A case study research. J Radiol Prot. 2016; 36(3):667. doi: 10.1088/0952-4746/36/3/667

39. Hoque MR, Bao Y, Sorwar G. Investigating factors influencing the adoption of e-Health in developing countries: A patient's perspective. Inform Health Soc Care. 2017; 42(1):1-17. doi:10.3109/17538157.20 15.1075541 .
40. Sellin N. On aggregation bias. Int J Educ Res. 1990; 14(3):257-68. doi:10.1016/0883-0355(90)90036-8.

41. Darmawan IGN. Adoption and implementation of information technology in Bali's local government: A comparison between single level path analyses using PLSPATH 3.01 and AMOS 4 and Multilevel Path Analyses using MPLUS 2.01. International Education Journal. 2001; 2(4):100-25.

42. Khoja S, Durrani H, Scott RE, Sajwani A, Piryani U. Conceptual framework for development of comprehensive e-health evaluation tool. Telemed J E Health. 2013; 19(1):48-53. doi:10.1089/tmj.2012.0073.

43. World Health Organization, International Telecommunication Union. National eHealth Strategy Toolkit [Internet]. Geneva: World Health Organization; 2012 [cited 2017 Jul 17]. Available from: http://apps. who.int/iris/bitstream/10665/75211/1/9789241548465_eng.pdf.
The Acta Medica Philippina is now accepting original scientific papers, review articles and case reports for its upcoming issues. Please follow the format for submission as indicated in the "Instructions to Authors" elsewhere in the journal. All papers received shall be properly acknowledged. For inquiries and submission of proposals, please email us at actamedicaphilippina.upm@up.edu.ph 